\title{
ТЕХНОЛОГИЧЕСКОЕ ОБЕСПЕЧЕНИЕ ПОДГОТОВКИ РЕГУЛЯТОРНЫХ АКТОВ В СФЕРЕ TPAНСПОРТА
}

\begin{abstract}
Обобщены научные подходы к определению технологии, иерархия функций, процедур и операций принятия регуляторных актов в условиях внешнеэкономической деятельности транспортного предприятия.
\end{abstract}

\section{1. ВВЕДЕНИЕ}

К приоритетным заданиям научного обеспечения эффективности развития транспортного комплекса в сфере внешнеэкономических связей отнесено предоставление методической помощи субъектам хозяйственной деятельности по вопросам научного обоснования транспортной инновационной, промышленной, социальной политики на долгосрочную перспективу, разработке методологии моделирования и прогнозирования социально-экономического развития регионов и административно-территориальных единиц, отдельных сфер деятельности, внедрения их в прогнозирование и обоснование первоочередных регуляторных актов (РА). Перспективные задания относительно определения приоритетной сферы ведения хозяйства по критериям социально-экономической эффективности для повышения результативности развития транспортных комплексов и повышения их конкурентоспособности также непосредственно связаны с процессами подготовки и принятие РА, которые требуют соответствующего методологического обеспечения, что и определяет актуальность исследований, результаты которых изложены в этой статье.

\section{2. СИСТЕМНЫЙ ПОДХОД К ПОДГОТОВКЕ РЕГУЛЯТОРНЫХ АКТОВ В СФЕРЕ ТРАНСПОРТА}

Системный подход в общем виде [3] и в сфере внешнеэкономических связей в частности - это одно из методологических направлений современной науки управления, связанное с представлением, изучением и построением организационных структур субъектов и объектов транспортного обеспечения как систем. Исходя из этого, основные понятия системного подхода: «система», «структура», «элемент».

Системный подход к транспортному обеспечению внешнеэкономических связей предусматривает анализ и синтез объекта управления, в частности РА. К основным заданиям системного подхода отнесены:

- разработка концептуальных (содержательных и формальных) средств

\footnotetext{
${ }^{1}$ Mgr Andrii Dmytrychenko, Katedra Prawa Transportowego i Logistyki Narodowego Uniwersytetu Transportu w Kijowie, Ukraina.
} 
представления исследуемых объектов как систем;

- построение обобщенных моделей систем и моделей разных классов и свойств систем, включая модели динамики систем, их целесообразного поведения, развития, иерархического строения, процессов управления и др.;

- исследование методологических принципов разных теорий транспортного обеспечения внешнеэкономических связей.

Системный подход не имеет фиксированной наглядной сферы. Он формирует характер, направление и стиль научного мышления при исследовании какого-либо процесса, связанного с решением вопросов транспортного обеспечения. При системном подходе выходят из того, что специфика сложного объекта (системы) не исчерпывается особенностями его составных элементов, а коренится, прежде всего, в характере связей и отношений между ключевыми элементами [2].

При этом следует учитывать, что диалектический метод в исследованиях в сфере транспортного обеспечения внешнеэкономических связей, составляющий основу системного подхода, предполагает:

- анализ транспортного комплекса как целостного объекта, в котором все явления и процессы взаимозависимы и взаимообусловлены;

- понимание того, что как транспортный комплекс, так и все его составляющие находятся в непрерывном и закономерном движении и изменении (обновлении, прогрессивном развитии или деградации);

- рассмотрение неизбежности внутренних противоречий как источника изменений.

Естественно, что объективно необходимые цели развития транспортного обеспечения внешнеэкономических связей должны быть конкретными, реальными и контролируемыми. В соответствии с избранной целью формируется стратегия и тактика деятельности и развития транспортного комплекса, разрабатываются прогнозы, программы развития, оцениваются результаты принятых РА и реализации мероприятий. Ориентация на цель должна достигаться в результате применения профессиональных управленческих технологий разработки и реализации РА в деятельности транспортного комплекса.

\section{3. СОСТАВ ТЕХНОЛОГИЙ ПОДГОТОВКИ РЕГУЛЯТОРНЫХ АКТОВ В СФЕРЕ ТРАНСПОРТА}

Технологии реализации регуляторных актов (РРА) - это искусство, мастерство и умение руководителя влиять на персонал для достижения общих и ключевых целей транспортного обеспечения внешнеэкономических связей. Технологии РРА предусматривают: методы и средства сбора и обработки информации; приемы эффективного влияния на персонал; принципы, законы и закономерности организации и управления; системы контроля.

Основой технологии РРА являются программы развития транспортного комплекса, которые представлены регуляторными органами в отрасли транспорта, прогнозы и концепции развития, которые касаются как самих органов, так и каждого должностного лица. Управление территориальным развитием транспортного обеспечения внешнеэкономических связей как вид профессиональной деятельности базируется на обоснованном применении технологий РРА. В отличие от технократических технологий (в машиностроении, 
металлообработке и т.п.) технологии РРА не является детерминированными. Поэтому нужна постоянная работа по усовершенствованию условий применения тех или других технологий РРА.

В состав технологии РРА в деятельности, направленной на совершенствование транспортного обеспечения внешнеэкономических связей целесообразно включить целевые технологии (ЦТ) РРА и процессорные технологии (ПТ), которые обслуживают целевые и являются относительно них инструментарием.

Целевые технологии включают инициативно целевую, программно целевую и регламентную технологии. ЦТ - это технология, основанная на приоритете целей транспортного обеспечения внешнеэкономических связей над ситуациями. ЦТ ориентирует решение на достижение цели, а не на устранение возмущающих действий. ЦТ представляет технологию РРА на предупреждение.

Основным предметом ЦТ является цель. Цель субъекта транспортного обеспечения внешнеэкономических связей или его структурного подразделения это желаемый и возможный для него, необходимый и приемлемый для потребителей процесс (явление).

Цели должны иметь определенную степень взаимосвязи с миссией субъекта транспортного обеспечения внешнеэкономических связей. Считается, что названная миссия - это декларация, которая представляет в совокупности короткое историческое описание субъекта транспортного комплекса и его деятельности, которая должна осуществляться; наименование глобальной цели управления, основной цели и конкретных целей деятельности; перечень принципов работы руководителя с подчиненными и потребителями транспортных услуг; социальноэкономические ориентиры деятельности; транспортную политику субъекта транспортного обеспечения.

При реализации ЦТ в деятельности субъекта транспортного обеспечения внешнеэкономических связей различают солидарное и пропорциональное авторство. Солидарное авторство - это уровни права руководителей и исполнителей на всю программу выполнения задания и результаты. Пропорциональное авторство - это права на всю программу и результаты задания или части их, которые определяются соотношениями расходов ресурсов (финансовых, материальных, интеллектуальных и др.) [4].

Инициативно целевая технология в деятельности субъекта транспортного обеспечения внешнеэкономических связей должна быть основана на определении заданий без определения средств и методов их выполнения и рассчитана на инициативного и профессионального исполнителя [2]. Инициативно целевая технология предусматривает разработку руководством субъекта транспортного комплекса только конечной цели задания для работника или группы, а также срока выполнения без определения механизма его достижения. При этом цель может быть не достигнута по каким-либо причинам, может быть достигнута в предусмотренные сроки или раньше, может быть достигнута за пределами установленного срока. Инициативно целевая технология предоставляет большое пространство для инициативных решений подчиненных [1].

Для этой технологии эффективна линейная схема организационных отношений в транспортном обеспечении внешнеэкономических связей. Профессионализм выполнения задания определяется квалификацией исполнителя задания, а квалификация руководителя играет вторичную роль. Технология не гарантирует 
достижения цели.

Чаще всего субъектами транспортного обеспечения внешнеэкономических связей должна применяться программно целевая технология. Она заключается в выдаче для исполнения заданий (целей, комплексов заданий) с указанием на средства, методы и время их выполнения, есть указания о внешнем или внутреннем контроле промежуточного состояния этого выполнения. Профессионализм выполнения задания определяется квалификацией руководителя, который выдал задание, а квалификация исполнителя играет вторичную роль. Программно целевая технология (ПЦТ) обычно гарантирует достижение цели.

Применение ПЦТ может привести к трем основным результатам деятельности субъекта транспортного обеспечения внешнеэкономических связей:

- достижению цели в заданный срок с приемлемыми отклонениями от заданных промежуточных значений;

- достижению цели в заданный срок при существенных отклонениях от заданных промежуточных значений;

- устойчивому не достижению цели в заданный срок.

Эта технология предусматривает разработку руководителем целей управления, средств и методов их реализации, а также сроков и состояния промежуточных значений процесса. Если какое-либо заданное промежуточное значение не достигнуто, то на его выполнение выделяются дополнительные ресурсы; если заданное промежуточное значение превосходит запланированное, то часть ресурсов переводится на другие потребности, и при этом цель будет достигнута в предусмотренные сроки.

Программно целевая технология базируется на современных знаниях, экономико-математических методах и информационных технологиях. Достижение цели управления с высокой степенью достоверности гарантируется. Эта технология формирует управление по предубеждению.

Регламентная технология заключается в выдаче для выполнения заданий (целей, комплексов заданий) с определением средств и их возможных ограничений, методов, которые рекомендуются, и ориентировочного времени их выполнения. Технология предусматривает наличие жесткого контроля процесса приближения к цели. Профессионализм выполнения задания определяется квалификацией руководителя, который выдал задание, и исполнителя. Предусматривается жесткий контроль за динамикой процесса выполнения задания

Использование регламентной технологии в деятельности субъекта транспортного обеспечения внешнеэкономических связей может привести к достижению ощутимых позитивных результатов от самого процесса достижения цели и отсутствию существенных позитивных результатов в течение определенного времени (топтание на месте).

Регламентная технология предусматривает разработку руководством субъекта транспортного обеспечения внешнеэкономических связей конечной цели управления и стратегий при возможном ограничении различных ресурсов (материальных, человеческих, финансовых и др.). При этом цель будет обязательно достигнута, но в сроки, которые трудно определить предварительно. Достижение цели гарантируется только при жестком внутреннем или внешнем контроле хода процесса реализации поставленных целей. 
Эта технология базируется на статистических методах, теории размытых множеств чисел, теории разработки решений в условиях неопределенности. Авторство на проект РА или программу и полученные результаты принадлежит руководителю и исполнителю.

\section{4. ВЗАИМОДЕЙСТВИЕ ФУНКЦИЙ УПРАВЛЕНИЯ В ПОДГОТОВКЕ РЕГУЛЯТОРНЫХ АКТОВ В СФЕРЕ ТРАНСПОРТА}

Структурами управления субъекта транспортного обеспечения внешнеэкономических связей, которые рекомендуются, является линейно функциональная структура, которая ориентирована на запросы потребителей.

В процессе разработки и реализации РА выделяют три ключевых субъекта: заказчик, разработчик и исполнитель регуляторного акта. Каждую фигуру могут представлять несколько лиц, групп или организаций.

Согласно общей методологии управленческой деятельности в теории управления разработка и реализация РА включает иерархию функций, процедур и операций [2].

Каждая конкретная функция (КФ) РРА должна предусматривать весь набор общих функций (ОФ), а каждая общая функция должна включать весь набор процедур (Пр), и, наконец, каждая процедура должна включать необходимый набор операций (Оп).

Функция в деятельности субъекта транспортного обеспечения внешнеэкономических связей - это совокупность действий, однородных по определенному признаку, направленных на достижение заданной цели и подчиненных общей цели управления.

К конкретным функциям РРА относятся разработка и реализация РА в следующих сферах: коммуникации с внешней средой; стратегическое планирование; управление персоналом; управленческое консультирование; управление сферами производства и услуг; управление управленческой деятельностью; формирование системы управления субъекта транспортного обеспечения внешнеэкономических связей (методология, структура, процесс, механизм).

В зависимости от трудоемкости и сложности конкретные функции РРА могут быть разделены на более мелкие. Каждая из них имеет свои особенности в разработке и реализации.

К общим функциям РРА отнесено:

- прогнозирование, связанное с методами разработки, реализации и возможными последствиями каждого РА;

- планирование состава и содержания избранных методов разработки и реализации будущего РА;

- организация (техническая, финансовая и др.) разработки и исполнения РА;

- стимулирование объектов, относительно разработки и исполнения РА;

- координация, то есть изменение принятого ранее порядка деятельности в связи с возникновением не предусмотренных ранее обстоятельств, которые мешают или способствуют его выполнению;

- контроль выполнения мероприятий;

- информирование инициатора разработки РА о ходе выполнения задания. 
Каждая общая функция может содержать два этапа и семь процедур. Этапы состоят из подготовки РА и их реализации. Полный набор процедур включает: информационную подготовку, разработку вариантов РА, согласования вариантов с привлечением соответствующих специалистов, выбор одного РА, утверждение (подписание) РА субъектом транспортного обеспечения внешнеэкономических связей, организацию выполнения, контроль.

Варианты схем взаимодействия функций, процедур и операций при разработке или реализации больших РА представлены на рис.1.

a)

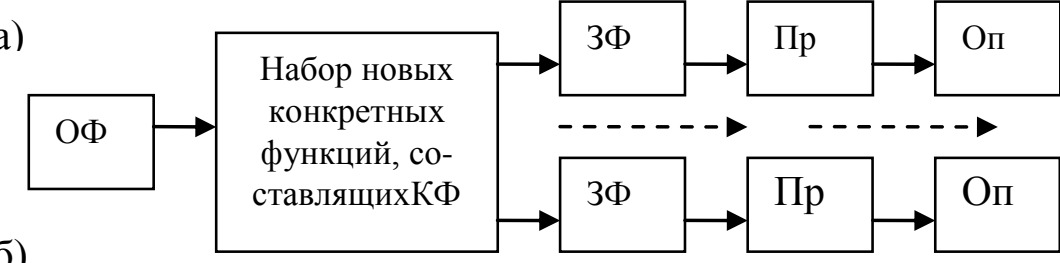

б)
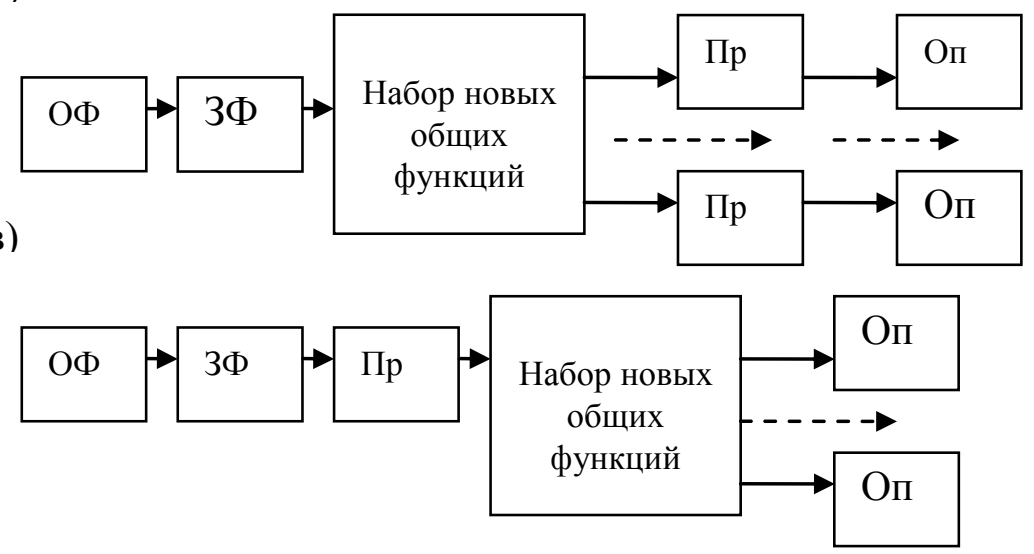

Рис.1. Схемы взаимодействия функций, процедур и операций при РРА: а) при типичном и масштабном характере конкретной функции; б) при типичном и масштабном характере общих функций; в) при типичном и масштабном характере процедур.

\section{5. ВЫВОДЫ}

Осуществлено обобщение научных подходов к подготовке и принятию регуляторных актов в зависимости от условий деятельности субъекта транспортного обеспечения внешнеэкономических связей. Охарактеризованы технологии РРА, как искусство, мастерство и умение первого руководителя или руководителей структурных подразделений субъекта управления влиять на персонал для достижения общих и ключевых целей транспортной политики. Технологии РРФ в сфере транспортного обеспечения внешнеэкономических связей включают целевые технологии (инициативно целевая, программно целевая и регламентная) и процессорные технологии. С использованием теории управления 
раскрыта иерархия функций, процедур и операций относительно разработки и реализации регуляторных актов в деятельности субъекта транспортного обеспечения внешнеэкономических связей, что позволит повысить его эффективность .

\section{ЛИТЕРАТУРА}

[1] Ефремов В. С., Проектное управление: модели принятия решений, „Менеджмент в России и за рубежом" 2008, № 6, с. 105-139.

[2] Ивасенко А.Г. Никонова Я.И., Плотникова Е.Н., Разработка управленческих решений: учебное пособие. - 2-е изд., перераб. и доп., Изд. КНОРУС, Москва 2008, 168 с.

[3] Парахина В.Н. Максименко Л.С., Панасенко С.В., Стратегический менеджмент: учебник, Изд. КНОРУС, Москва 2006, 267 с.

[4] Management Concepts and Techniques//Digital Equipment Corporation. USA, 2004. - 234 p.

\section{TECHNOLOGICAL PROVIDING OF PREPARATION OF REGULATORY ACTS IN THE TRANSPORT FIELD}

The scientific approaches to determination of technology, hierarchy of functions, procedures and operations of acceptance of administrative decisions in the conditions of foreign economic activity of a transport enterprise are generalized.

DOI: 10.7862/rz.2012.zim.17 